\title{
From customer data to value: What is lacking in the information chain?
}

Received: 1st August, 2006

\section{Dominique Crié}

is Professor of Marketing at the Institut d'Administration des Entreprises at the University of Sciences and Technologies in Lille. He manages two masters degree courses in Statistical Specialisation for Marketing Databases and Marketing and Commercial Surveys and Analysis. He is also a marketing consultant and statistician. Professor Crié is a member of the Association Française de Marketing and of the Société Française de Statistiques.

\section{Andrea Micheaux}

is an associate director at Analyse Informatique des Données, a company that specialises in database marketing. She is also an associate professor at University Paris 1, where she teaches both relationship marketing and customer relationship management.

Abstract Based on literature and practical experience, the authors define and discuss the customer data to value information chain. From data collection, through data quality management, performance metrics and knowledge management, optimising the various links in the chain leads to superior customer service and more profitable customer relationship management. Various current weaknesses are identified and recommendations made for improvement.

Dominique Crié Institut d'Administration des Entreprises

104, avenue du Peuple

Belge

F-59043 Lille Cedex

e-mail: domicrie@aol.com

\section{INTRODUCTION}

In the nearly 20 years of practice since the first customer databases were built by banks, credit and catalogue sales companies in the mid 1980s -

businesses have matured in terms of their knowledge and expertise in collecting, interpreting and using data for decision making and commercial action. Today, customer knowledge is considered to be one of a firm's most valuable resources. The explosion in direct channels to the customer, such as e-business, call centres and loyalty card programmes, has produced huge volumes of data, which are being channelled into customer relationship management (CRM) databases for use in targeted relationship marketing and statistical modelling of consumer behaviour.
In theory, this enhanced customer knowledge should produce improved business results. In practice, however, many companies are still at the data storing and exploratory stages and have not seen the tangible benefits of the transformation of an organisation from being product-centric to being customer-centric, which CRM should be forging. From the customer viewpoint, increasing expectations for personal recognition and improved quality of service are not fulfilled, causing dissatisfaction. From the firm's perspective, the struggle to realize profits from CRM investments is still in progress.

The authors believe it is still early in the process. Companies will change in order to eventually dominate this new 
technology and multiple sources of data. While it is difficult to imagine the ultimate picture, at this point several weak links in the chain from raw data to value for customers and firms are obvious.

This paper focuses on four aspects of the CRM data value chain:

- Obtaining the right data;

- Data quality management;

- Deriving information and knowledge from raw data; and

- Using information and knowledge to satisfy customers and generate profits.

Many companies are already working in one or several of these areas but to the authors' practical knowledge, no one organisation has implemented all four elements in a simultaneous and concerted fashion, nor is there significant understanding of the synergy between them.

Numerous factors contribute to dilute the potential power of the data in each of these elements. Specifically:

- Databases do not necessarily contain the right information.

- In practice, data quality control and knowledge management are not implemented in most organisations.

- Too few employees are trained in the handling and analysis of data, or in managing the information system (hardware and software).

- Employees are not sufficiently empowered to correctly use the information delivered in order to satisfy customers.

- Senior management is not sufficiently motivated to support efforts in improving the data-value chain, due to lack of metrics proving the impact of CRM data and marketing operations on the bottom line.
Finally, organisations are more likely to be aware of the importance of customer data at a micro level (targeting customers individually, using the information in vendor-customer relationships) than at a macro level (strengths and weaknesses versus competition, opportunities for innovation etc.) The difficulties in achieving a complete information value chain are, in part, technical, but are mainly due to organisational and human failings.

The purpose of this paper is to highlight the weak links, to provide an overview of current progress and to encourage companies to engage in an holistic view of the data to benefits chain, pulling customer insight, data quality management, marketing performance metrics and human resources aspects together for tangible impact on profits and value to the customer.

\section{OBTAINING THE RIGHT DATA}

The first step to forming an information chain which aims to provide excellent customer service and profits for the firm is to capture the right data. This involves recording the data correctly and as exhaustively as possible, choosing which variables to store (transactional, relational, psychographic, aggregated versus raw data etc) while complying with privacy regulations and deontology.

The central question is what kind of data to store. A simple decision rule before creating any data field is to know what one will do with it. Information overload hinders the search for knowledge. On the other hand, the lack of certain data, such as email addresses authorised for commercial proposals by their users, could be costly for an organisation if the only alternative is direct mail. Successful customer modelling is about 80 per cent dependent on having the right data for 
analysis. ${ }^{1}$ Often marketing models fail for lack of external validity (ie they are not generally applicable to new populations) or because they do not adequately describe the variables and relationships in the true system being modelled. This is often due to missing information. ${ }^{2}$

The main objective is therefore to gather data that are both relevant and actionable for company strategy and for customer relationship management.

From the customer's viewpoint, the firm should hold information which saves the customer from having to repeat his or her profile and relationship history. The learning history which has built up over time is one of the main contributors to customer loyalty. ${ }^{3}$ The cost of changing supplier, particularly in

business-to-business relationships from which relationship marketing evolved, is seen by consumers as being fairly prohibitive unless an unsatisfactory incident or a significantly better offer motivates them to reinvest in the mutual learning process elsewhere. Transactional and relationship data are necessary for this level of knowledge.

Beyond learning the factual behavioural profile and history of a customer, deeper insights into the benefits sought from the relationship, attitudes and the customer's relationship with the brand or product category are important for giving the impression that the customer is being listened to.

Perceived empathy is a key factor contributing to a positive evaluation of the firm as a relationship partner. ${ }^{4}$

From the firm's viewpoint, homing in on what is important and relevant to the customer is essential to maximising the impact of communication, sales arguments and direct marketing response.

While purchase behaviour, relationship history (such as preferred communication channels), sociodemographic profile and economic potential (such as household shopping budget or estimated office supplies consumption for a business) are useful in understanding a target's needs and developing appropriate marketing actions, the authors believe that, especially in the consumer market, 'psychographic' data — such as attitudes, benefits sought and even personality traits - will prove to be increasingly important in leveraging value from the powerful relevance factor that is only just beginning to be understood.

There are several ways in which individual psychographic data can be captured. One way is to identify key 'golden questions' to ask the customer on loyalty programme membership questionnaires, via the call centre or the salesperson. ${ }^{5}$ Another way is to statistically extrapolate a cluster system derived from a survey. ${ }^{6}$ Increasingly, companies will use customer collected verbatim from emails, letters and even telephone calls to derive attitudinal knowledge.

In sum, ensuring the database systems contain the 'right' data requires answers to the following questions:

1 What data do we potentially have available?

2 What data are needed to achieve our goals?

3 What data are missing that we ought to have?

4 What data will be necessary in the future in order to address the market?

Once missing data elements have been identified, priorities need to be set. This can be achieved by cost-benefit analyses (what is the cost impact of the missing data in lost business opportunities, erroneous communication or inadequate customer service?) and also by taking into account the necessary budgetary and human efforts (what operational strategy should be put in place to obtain these data?). 


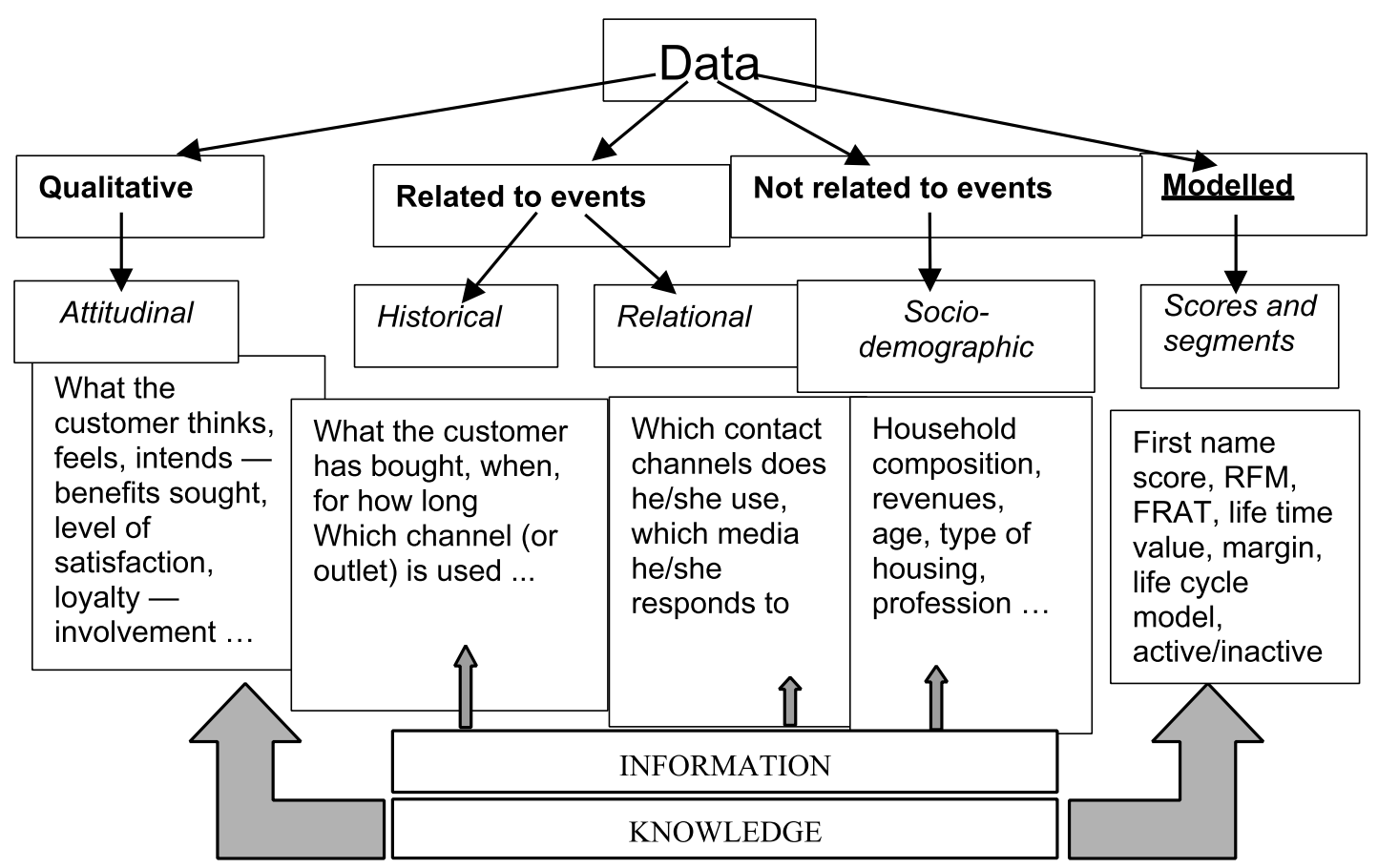

Figure 1: A taxonomy of data types

\section{Behavioural vs attitudinal data}

Generally, behavioural data are easy to collect: they are mainly quantitative data detailing the customer's transactional dealings with the firm. On the other hand, it is rather more difficult to gather data concerning what the customer thinks; that is, attitudinal data that do not directly reflect behaviour but the state of mind of the customer.

To date, databases have essentially contained transactional data, due to their availability and also to the transactional nature of marketing thought. Recently, relationship marketing has changed the ways in which business operates and has highlighted the need for other kinds of data — such as people's interests, perceptions, preferences, beliefs, degree of involvement or criteria of choice, reactions to alternative offers - and also what channels customers use to contact the organisation, what kind of ads they respond to, what kind of people they talk to, what kind of lifestyle they have and so on. These data should be gathered within an opt-in or permission marketing framework because of their highly personal nature.

Some authors have a poor opinion about the quality of subjective data, whether for building marketing models (see, for example, Leeflang \& Wittink ${ }^{7}$ ) or for other uses. Even if a customer may form evaluative contextual judgments relative to some particular decision situation, this type of data could provide new insights into customer behaviour. Attitudinal data enhance customer knowledge because they are directly connected to the customer's inner thoughts.

Figure 1 provides a taxonomy of the various types of data available to marketers.

Information can be extracted from event-related or other data. Matching information back to data leads to knowledge. For example, a customer's age may be estimated using first name scoring; the probability of him/her responding to an offer can be calculated 


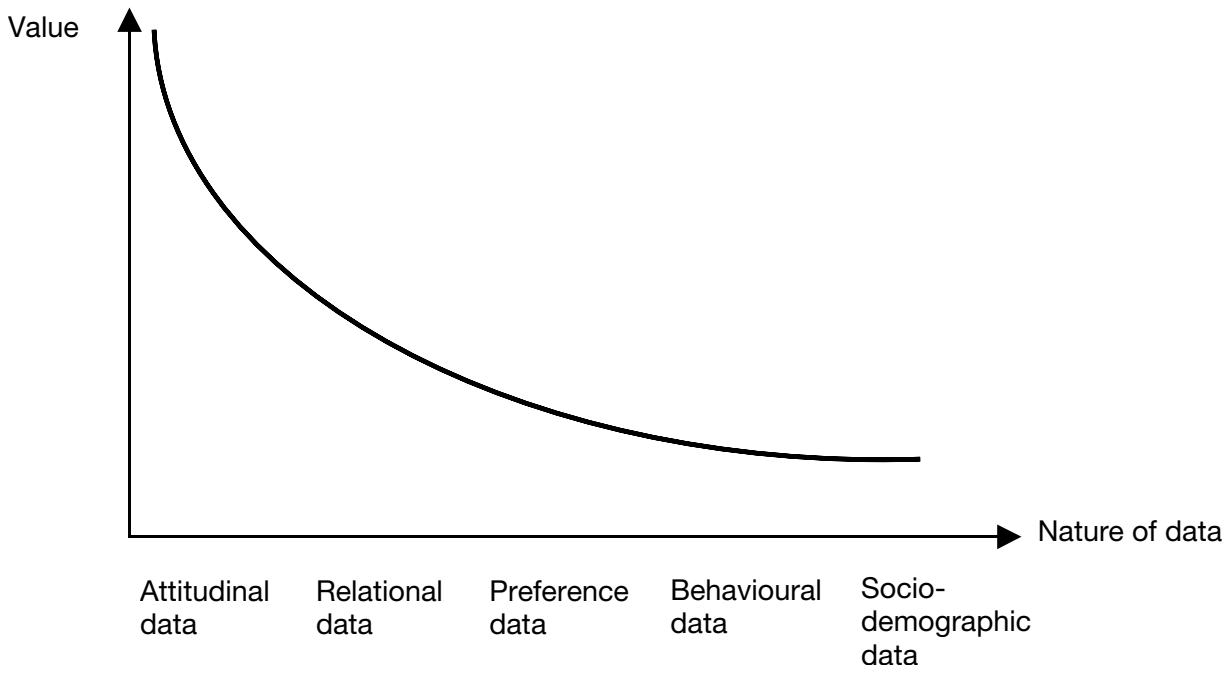

Figure 2: Data value for delivering better customer experience

using a recency-frequency-monetaryvalue (RFM) score or frequencyrecency-amount-type (FRAT) score. Life time value (LTV) represents the value of the customer over the entire relationship. Customer knowledge is derived from theses variables and is used to deliver improved customer experience and for managing the relationship. Attitudinal data should also be part of this knowledge and should be more systematically integrated into databases through questionnaires, for example on loyalty card membership forms or other sources such as written or verbal exchanges with the customer. Figure 2 summarises the various values of the different types of data for delivering better customer experience along a continuum.

\section{Aggregated versus raw data}

Within the information chain, aggregated data will contribute both to decision making at a strategic level and to providing the basis for marketing action. The level of aggregation is often chosen based on a cost-opportunity analysis. For Wedel, Kamakura and Böckenholt it seems unnecessarily restrictive to take an individual-level approach as a central paradigm for marketing modelling and marketing action. ${ }^{8}$ If this is true within a direct marketing perspective, where messages are often targeted at household level or differentiated at segment rather than individual level, it is not so within a relational person-to-person exchange where every individual must be considered as unique. Segmentation data can still be useful in guiding an exchange with a customer, however (for example, by differentiating their expectations). Once again, cost is one of the main reasons for deciding which level to apply, particularly with regard to the available information technology systems.

Nevertheless, whether customers should be segmented or targeted one by one remains a marketing rather than a statistical decision. A general tendency of both practitioners and researchers is to use raw data, ${ }^{9}$ a common situation in the industrial sector. Databases enable marketers to capture details of customer behaviour, and analysis of past behaviour enables prediction of the likely evolution of future trading relationships, especially if attitudinal data are available. 
Traditionally, and particularly in mail order industries, aggregated data are commonly used and seemingly preferred. The best known and best used models ${ }^{10}$ are RFM or the closely related FRAT model, which extends RFM to include product type. Another aggregated datum is the $r$ coefficient $\left(r=1 / \mathrm{CV}^{2}\right)$. described by Morrison, ${ }^{11}$ which identifies customers who exhibit regular purchasing patterns (however, it is rarely used in this way). This coefficient is the inverse of the square quotient of standard deviation (std) calculated on the average (avg) inter-purchase span at individual level. If inter-purchase spans are regular, the standard deviation is close to zero and $r$ is high (>10 in practice). Purchase regularity, which is closely related to the buying frequency indicator, is one of the principal measures of customer loyalty. ${ }^{12}$

Such aggregated data or scores usually produce good results and, again, it is better to work with robust aggregated data than with inaccurate individual datum points. As a general rule, it is worth using such data in CRM when customer needs are fairly homogeneous within a segment. It is also useful for investment decisions and return on investment (ROI) analysis. On the other hand, if customer-facing employees have to deal with such innovative techniques as context-sensitive response, that is to say obtaining recommendations on a course of action, detailed customer characteristics and history must be available in addition to the aggregated data on which the recommendations can be based. In short the level of aggregation should be adapted to the goals sought by the firm.

\section{Privacy}

One cannot discuss data collection without mentioning privacy laws. Legislation (eg data protection acts and the EU Directive on data protection) or codes of practice in various sectors of the economy are emerging throughout the world. These establish a variety of principles for the handling of personal data and have a strong impact on the gathering of data and their use even within permission marketing practices. ${ }^{13}$ For Stone et al., ${ }^{14}$ information privacy refers to: "The ability of the individual to personally control information about one's self.' The respect of privacy goes beyond the mere application of laws and regulations. It is part of organisational ethics. There is a paradox between data completeness and the privacy concerns of customers. When a firm attempts to collect private data, people can be reluctant to disclose personal information. In particular, there is a perception that giving personal information will trigger unwanted direct marketing, telephone marketing or spam from organisations that the individual has never heard of. Consumers often raise such concerns about privacy and the possible abuse of information. In this way, respecting privacy can be a barrier to obtaining the most pertinent data for marketing strategic and tactical decision making and action. On the other hand, the authors' experience has been that when questions are asked which are coherent with the nature of the relationship, consumers are willing to provide the information necessary for improving customer service. The difficulty lies in meeting customer expectations aroused by this data collection.

\section{DATA QUALITY MANAGEMENT}

Identifying the right data to collect is one end of the customer data to value chain. Ensuring the quality of the data is the next, vital, step towards maximising returns from the data for the firm and the customer. 
Fundamentally, data is factual and database data should represent 'the truth'. Data should be robust, ie it should accurately provide the information it is intended to provide. For example, date of birth. Although all customers have one, this may be unreliable in certain cases due to agents keying fake values, such as 99999999 or 010101, into an obligatory field when they do not know the information (or do not like to ask). This naturally has serious consequences in terms of lost business opportunities; for example, targeting clients reaching certain age ceilings for insurance premiums or in calculating scores which would optimise targeting (age being one of the most discriminate variables in consumer models).

Data must be fresh. This is particularly important for the customer's postal or email address, but also for any transactional data and scores and other calculated models, since customers can migrate from one segment to another. For example, one way of identifying a customer who is at risk of leaving is by noticing that he has fallen from a loyal to a less loyal segment. Data are perishable and accuracy declines rapidly. Stone et al. report they found in a test for a client that only 64 per cent of the identifying information for customer records was accurate. ${ }^{15}$ The customer database of a group of opticians in France was found to contain up to 14 per cent of goneaways according to date of entry.

Data should be as exhaustive or as complete as possible: missing Standard Industrial Classification (SIC) codes or Dun's numbers can seriously hamper prospecting activities as prospects are prioritised according to sales potential evaluated based on line of business and employee size while the Dun's number enables the updating with the latest contact data and creditworthiness information. Other data quality issues such as uniqueness (avoiding duplicates) and compliance (such as compliance with telephone number or postal normalisation formats in different countries) impact on both cost to the firm (for example, sending out duplicate mailings) and perceived image from the customer viewpoint.

While some multinational corporations are working seriously on data quality procedures, ${ }^{16}$ generally speaking, data quality is not handled well by database managers. Nowadays, the topic of data quality assessment is to the fore as, having installed CRM systems, many marketers and sales teams have seen results of their actions depleted due to poor data quality. Most corporate data show inconsistencies, but the actual quality of the information is not well known and the whole data quality issue is often treated in an offhand manner. Managers talk about their data quality concerns, but few managers do anything about them. The need to keep data as clean and healthy as possible, however, is of a strategic nature. ${ }^{17}$ Moreover, the impact of poor data on operations, results and customer perception does not often reach higher management levels due to lack of measurement and formalised data management programmes.

At base level, although every database manager seeking high quality data, ${ }^{18}$ it seems that marketing practitioners in particular are not sufficiently aware of how to define a quality datum point.

Very simply, quality data are data which are fit for purpose; ie relevant to marketing actions and decision making and fit for use. Considering fitness for use, there is a general consensus in the literature that data should be:

- Complete (ideally 100 per cent filled)

- Fresh (reflecting the current real world situation) 
- Unique (no duplicates where data should be grouped, for example, no duplicate contacts or duplicate household data for the same household)

- Valid (compliant with required formats and patterns, such as telephone formats; no fake values — such as 999999 — or false values; consistent between different sources and subsystems).

Data quality procedures involve calculating and tracking data quality indicators periodically through random sampling and a systematic screening. Clément and Laboisse describe audit procedures and metrics used for data quality control in a multinational organisation applied to marketing and commercial data from multiple data sources. ${ }^{19}$ Among others, Worthington and Brilis have developed a check list for assessing data and information quality. ${ }^{20} \mathrm{~A}$ good data management system should include checks on data entry and data source(s) to keep garbage out: with poor data entry validation, even a good data management system will generate garbage if garbage is input. Moreover, incorrect data can propagate to other systems and cause considerable, widespread damage. ${ }^{21}$ For example, a customer or prospect identifier is often automatically allocated from a central register when a new account is created by the salesperson. In one particular case, if the salesperson took too long to create the new entry, or was interrupted, a system time-out caused the customer ID to be cancelled - unknown to the agent - and allocated to the next entry. This anomaly was propagated through to other systems matching customers to orders, the end result being erroneous invoicing.

The knowledge of the level of data quality provides managers with important information for managing and improving processes. The hidden costs of poor data quality are numerous - and certainly high — but are seldom assessed. For example, incorrect data can lead to reduced productivity from time lost in problem solving, de-motivation and loss of confidence in database tools.

Incomplete data, such as missing telephone numbers, can lead to missed business opportunities, particularly in business-to-business activities. Data quality issues are also a common and important source of suboptimal analysis and modelling effectiveness. ${ }^{22}$

Measurement of data quality levels, tracking improvement or deterioration of quality levels over time and evaluation of the cost of poor quality leads to firms focussing on key areas for improvement. Once corrected, this has direct impact on profits as well as improved perception of the quality of the relationship from the client standpoint.

\section{Marketing performance metrics}

Metrics are key elements of the customer data-to-benefits chain. To date, the focus has been mainly on the data itself with, as has been described, efforts to collect considerable amounts of data fit for purpose and fit for use in piloting and managing the customer relationship.

Secondly, companies have been transforming raw data into information and then knowledge and using that knowledge for marketing decision making and action. The measurement of both data quality and marketing performance resulting from the acquired knowledge is a recent innovation, however, and is not, as the authors believe it should be, an integral part of the value chain in many instances.

While direct marketing practitioners have been using customer data to track response for many years, there is room for improvement by bringing on board 
systematic measurement of marketing efficiency across all media channels and drawing this information together to maximise budget allocations. A very basic datum, regularly ignored, is the cost of reaching a customer with an offer or communication whether above or below the line. Campaign budgets are stored as estimations or actual counts of the volumes of customers or prospects reached; however, these are not often stored at an individual level in the database. Automated campaign management systems are beginning to enable the allocation of unit costs calculated at the inception of a campaign. These are quite simply the campaign budget for the channel (creative and unit costs) divided by the number of targeted individuals. When matched with subsequent purchases this basic element provides for the calculation of ROI, but this is not the only use. Over time, the cost of successive campaigns will build up and differentiate the levels of marketing investment for individuals and segments. Overall profitability of marketing efforts can then be measured and investment reduced or increased as necessary. Although not often directly built into the database, above the line media — such as television, web banners, radio and newspaper advertising - can also be taken into account. Costs to reach (defined as investment necessary to reach an individual who remembers the campaign) and results in terms of purchase intent or actual sales, if available, can be obtained through telephone or online surveys carried out on samples extracted from the database and stratified by segment. These average results are then panned out across the database and can be used in conjunction with the more readily available direct marketing data. From this base, marketing budgets can be optimised using automatic tools such as SAS MO, and optimised campaign plans executed. Expected results based on past history are fed back into the system and compared with actual measurements when these become available.

An interesting link between these individual level ROI metrics and data is anchored in the concept of the cost of poor data quality. Levels of data quality, measured and stored as indicators, can be linked to direct and indirect costs. ${ }^{23}$ For example, the cost of a wrong or incomplete address leading to an undeliverable can be estimated at $€ 0.8$ or the average cost of a mailing. If the number of incomplete or wrong addresses has been measured by data quality metrics, then the total annual cost of poor data, in terms of undeliverables, can be calculated for each poor quality record as:

Number of times per year record is targeted for direct mail $\mathrm{X} € 0.8$

Over and above this simplistic measurement, much of the cost of poor quality data resides in lost business opportunities. For example, having no opt-in email for a business contact means the firm cannot carry out emailing campaigns towards the individual. Past results from marketing performance metrics can be translated as the opportunity cost of not having a valid opt-in email. In one business-to-business case, opt-in emails were evaluated as having an average annual revenue potential of $\$ 388$, based on the prior information that for every dollar invested in emailing, $\$ 388$ of sales have been generated. If the database holds 30,000 missing emails, the opportunity cost of this unavailable data amounts to over $\$ 1$ million. This is worth some additional investment in permission email collection, even if this entails visits or 
telephone calls by the sales staff. There are, therefore, direct links between evaluating marketing performance, storing these metrics as individual data and the quality of the database itself.

\section{DERIVING KNOWLEDGE FROM RAW DATA}

Although in everyday discourse the three terms are interchangeable, the difference between 'data', 'information' and 'knowledge' is crucial, because their usage varies tremendously as is highlighted below.

While 'data' refers to raw material to be processed, 'information' is derived from significant regularities residing in the data that individuals attempt to extract. 'Knowledge' is a set of expectations held by individuals which is modified by the arrival of information. ${ }^{24}$ In this light, one can also define knowledge as theory awaiting confirmation via the information. Extracting information from the data, and knowledge from information, constitutes an act of interpretation. As such, gathering raw data, deriving information from it and contributing to knowledge are integral elements of the data-to-value chain.

While the transformation of data into information is fairly readily understood, the step from information to knowledge is a different process which can be difficult to master.

Globally, unprocessed raw data are collected, formatted and subsequently investigated to find relationships between variables. The information thus derived can then be used for commercial or industrial purposes. In many cases, particularly in mail order industries, action does not require deep knowledge of the situation and can be triggered directly by information: this is sometimes called 'inform-action'. The greater the volume of information, the more intelligence the user will accumulate about the subject in hand, until a certain level of profound understanding is reached: knowledge. Once in possession this knowledge, further attempts to extract information will become easier to due to a clearer view of the overall picture with the probable result of generating richer and better quality information.

Data collection, information and knowledge are chained together in a loop. Prior knowledge or theory guides the user in determining which data should be gathered. Likewise, deeper analysis of existing data may reveal hidden patterns and relationships leading to the discovery of new insights. This, of course, will depend not only on the underlying knowledge or theoretical concepts but also on the manager's analytical skills.

The nature of this cycle indicates that the database itself ought to be constantly improving through deeper understanding and the gathering and storing of more relevant data and better targeted, more efficient analysis. This is rarely the case, however, due to the presence of a static database structure, which breaks this virtuous circle. ${ }^{25}$ Data of such importance to the firm should continuously be upgraded over time as part of a continuous process that converts raw data into knowledge within a decision-making framework. Many businesses see data collection as a discrete activity, however, and as a result, contact employees often have to make do with outdated or incomplete information, which, in turn, leads to unsatisfactory customer experience.

Data requires structure and analysis to enable transformation into information. This requires an understanding of data and an appropriate framework for interpretation. For example, if a retailer 

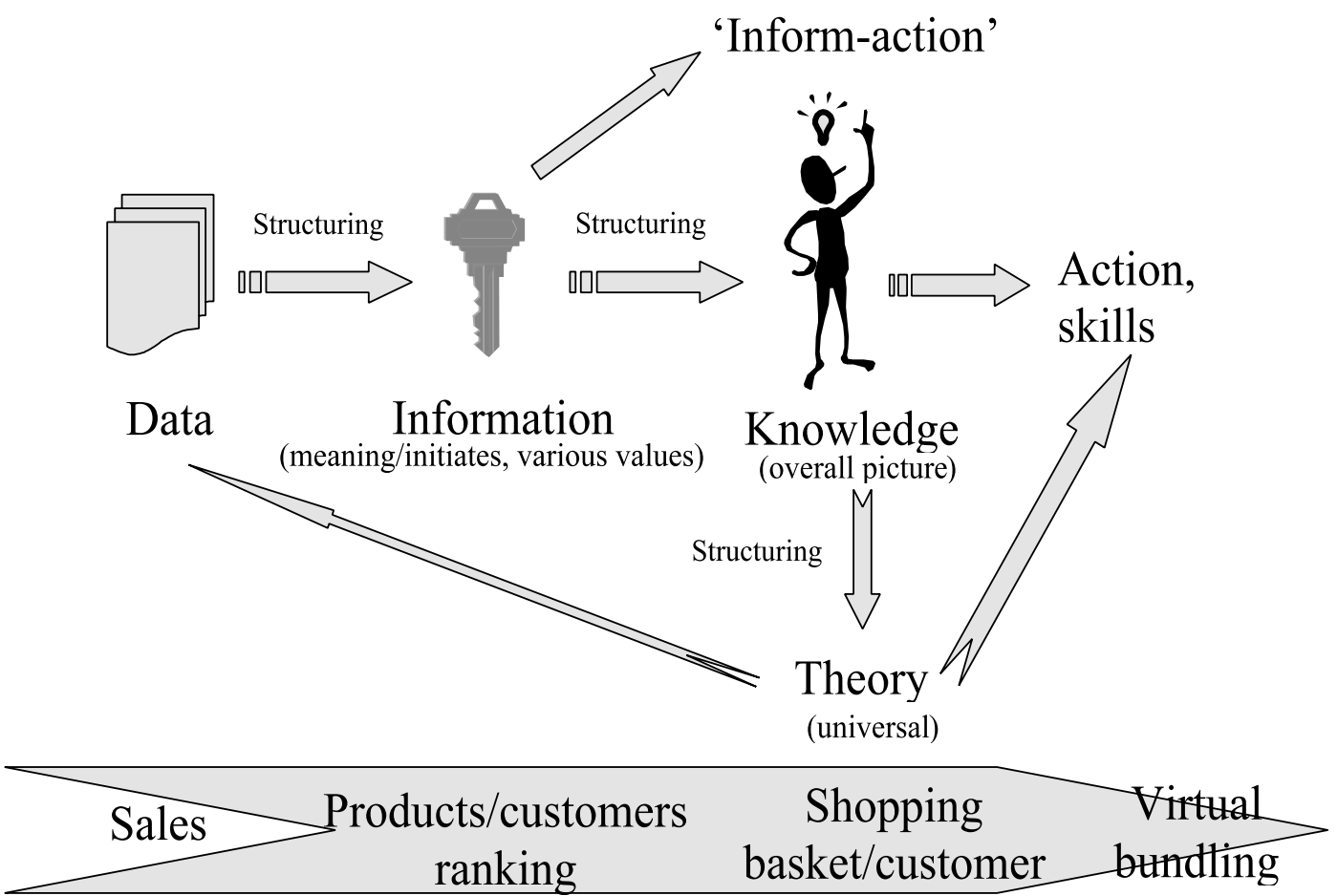

Figure 3: From data to theory, skills and action

notices that a customer makes infrequent visits to the store and always buys the same item:

- Data $=$ customer X buys only A;

- Information $=$ he/she probably likes A, he/she probably does not find A in his/her usual store.

In this case, the retailer cannot derive knowledge from this information as he does not know the characteristics of the customer's other shopping habits and therefore has no framework within which to form any hypothesis.

Through analytical transformations, the value of information or knowledge can be increased, improving the usefulness of the original data for end-users within the organisation, helping them to make better decisions with the aim of pleasing customers. For example, as shown in Figure 3, raw sales data can be structured by product category, customers can be ranked by sales or categorised by product typology. Frequent patterns of basket content can be identified. The resulting customer knowledge may suggest a targeted virtual bundling promotion with a high probability of response.

The value or meaning of information will depend on the interpretation of the individual who receives it. Like knowledge, information cannot be assumed to have a fixed value independent of the receiver. The information valuation process is dependent on the relationship between in-coming data and the individuals for which it is destined. Only prior knowledge enables a contextual understanding of new information. The enriched knowledge as a result of the value added by the new information will in turn become improved prior knowledge as a basis for further 


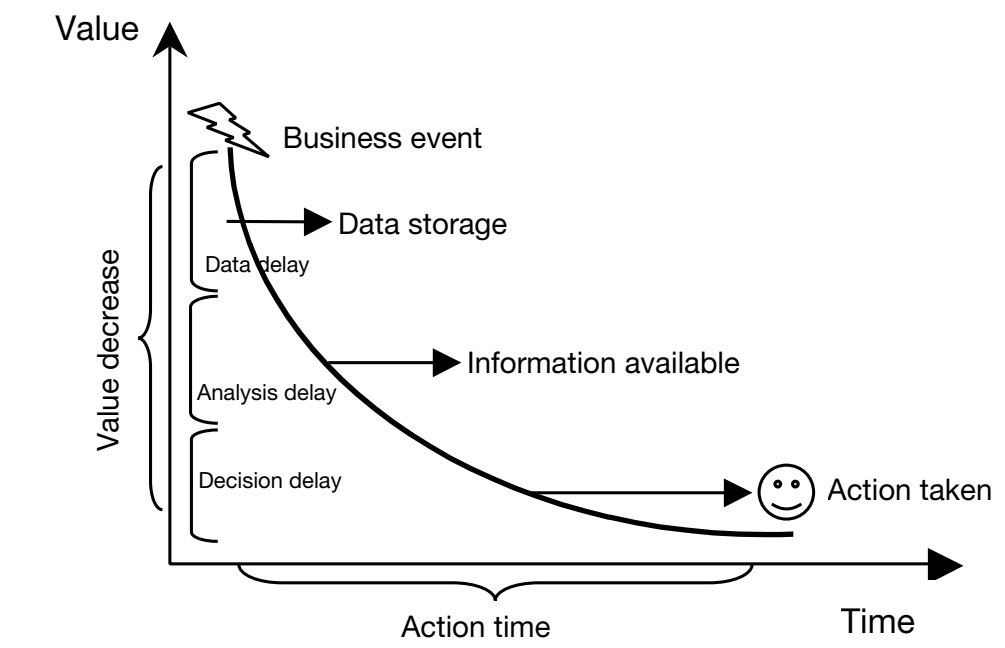

Source: adapted from Hackathorn 30

Figure 4: Components of action time

information processing. Therefore, not only does the database need to reflect the continued improvement of knowledge by an ever more relevant data content, the individuals who are to use and evaluate the data must have sufficient analytical skills to interpret it and sufficient prior knowledge to do so in the most appropriate framework.

On the other hand, it is important that data should also be analysed as rapidly as possible and made available to operational systems and employees. Timeliness adds value to information. This is a basic rule: generally, the value of raw data decreases rapidly as it ages. Only the accumulation of new data and refreshment of databases lead to increasing information about a given customer. Businesses need more and more real-time data. The overall time spent in processing the entire sequence from data to knowledge must also be minimised: identifying available data; data acquisition; processing and analysis; communication; use for decision making; action; customer experience leads first to ROI and secondly to knowledge about customers and the market in general.
For Hackathorn, there are three kinds of latency or delays that put a strain on data value and consequently on the relevance of the action taken (Figure 4). ${ }^{26}$

The first is data latency which is the time required to capture the data, generally from a transactional event, and store it in the database. The second is analysis latency, which covers the time taken to analyse the data and provide the right employees with the results enabling them to make the right decision. One example of this is a health insurance company which experienced a decline in its customer volume. This could have been avoided if the information about the reasons for customers cancelling their policies had been available. It transpired that flagging loyalty was not the reason behind the defection but death due to an ageing customer base which was, therefore, not being renewed. Earlier discovery of this trend would have had significant impact on the business.

The third type of delay is decision latency, which is the time required for the appropriate employees to understand the information and make the right decisions for action. Many decision 
processes in marketing are automated which reduces decision latency. One example is automatic follow-up of customers who are detected to be at risk of leaving. Companies should strive to integrate and communicate the data to decision support and front office employees as quickly as possible. In context-sensitive response situations, front desk staff should be able to type notes into a computer in real time and obtain recommendations on a course of action, being provided with data items available about the customer in order to assist with decision making during the service encounter. In the same way, data scores and segmentations can also inform employees about the nature of the client and different scripts or product offerings can be automatically displayed. For example, a consumer credit company uses an attitude-based segmentation to allocated inbound calls to specialised agents who use an automated script system to ask specific questions necessary to further qualify the customer and propose pre-determined products designed for this segment.

If the first two latencies can be reduced through technical solutions, the third, when processing is not automated, depends on how knowledge is managed within the firm and how salespeople use the information to deliver the best service to the customers. ${ }^{27}$

For the person who knows how to put it in perspective, information is the foundation for future action; for the user, it provides the capacity to implement action which will influence the environment. Furthermore, despite the fact that data are now widely at hand, many organisations lack the human skills and knowledge necessary to analyse the data efficiently enough to be able to create information and knowledge that can be used to improve the customer experience.

\section{KNOWLEDGE MANAGEMENT}

The information chain is embedded in organisational decision-making processes and employees are not always well trained in handling data, managing the system (hardware-software) and delivering a productive customer experience.

Successful knowledge management, however, should empower employees to proactively understand, implement and take action that enhances customer trust and commitment as well as increasing the transaction stream. For the purpose of the authors, knowledge management is a continuous process with the objective of ensuring that every employee in the organisation has access to relevant information in order to achieve excellence in the customer relationship. Three vital components underlying this process are:

1 Information technology;

2 Human resources;

3 An organisational structure which favours the distribution and sharing of knowledge.

Knowledge management is defined as the process of capturing and recording a company's collective expertise (the whereabouts of these records being internal or external databases, documents of all kinds and formats or even in individuals' heads) and finally its redistribution in such a way as to generate the highest profits.

\section{Various aspects of knowledge management}

Knowledge management raises numerous polymorphic and complex problems. For example, the same set of data or information can lead to different knowledge or behaviour in the hands of different individuals as 
well as for the same individual at different moments in time. On the other hand, ensuring that information or knowledge is stored does not guarantee that it will be used. To this end, the knowledge lies in the user and not in the collection of data.

\section{Technological aspects}

The management of knowledge equity is not limited to the extraction of information using new technology. These tools, due to their user friendliness and the ease of interpretation of results, make a valuable contribution to the process of sharing knowledge. They facilitate the task of structuring the intelligence and experience of individuals in order that the right information should be accessible to the right person at the right time. The recipient then has to select the information which is potentially useful for the organisation in a given context and space of time. Of course, staff need to be trained to use these tools. Training is not always as thorough and as widespread as it should be, due to time and budget constraints.

\section{Human aspects}

Knowledge has cultural and even emotional connotations. Knowledge management is rooted in human resources as it positions the individual at the heart of the system, can revolutionise the way work is carried out and, like quality assurance, is a transversal function. At the present time, however, it seems that few employees are involved in the system in reality. From an operational point of view, reward mechanisms should be established to stimulate staff. Recognition of their skills should be conveyed by responsibilities and increased autonomy favouring the quality of the relationship to the customer.

\section{Organisational aspects}

Intrinsically, the process of knowledge management is the germ of substantial organisational changes. All too often it takes the limited shape of an intranet, offering a few specialised tools, while in reality the exercise and distribution of power are at stake.

Information should be placed at the centre of the organisational structure and used to control how work is carried out. On the other hand, the organisational dynamics will have to respond to obstacles in knowledge sharing and favour an innovative attitude.

Information and knowledge also impact on production, such as, for example, the customisation of products and services based on customer insight. In this way, firms should encourage the emergence of shared knowledge, where every individual participates in its production and distribution. At the same time, it is worth developing a pluricultural as well as cross-cultural spirit, bringing together people with different cultural and knowledge backgrounds such as marketing people and computer specialists.

Increasing proficiency among personnel, improved productivity and more flexible cultural dynamics lead to, amongst other benefits, innovation in products and services, an increase in value delivered to customers, enhanced management of the customer relationship, more efficient resolution of problems through service recovery, reduced costs and, overall, a keener competitive advantage. Through acquired knowledge, the learning company is in touch with the market, it anticipates the needs and expressed or latent desires of its customers and is able to offer the appropriate products. Knowledge improves the performance of the company through positive change in staff and organisational behaviour. 


\section{Obstacles to high-quality knowledge management}

Within the current context of constant change, management of collective knowledge encounters numerous obstacles in terms of organisational factors and human power games, not forgetting cultural dimensions and the high cost of access to new technology.

In addition, many companies are wasting effort in collecting and storing data by not allocating the means to assimilate and use it for operational or strategic purposes.

Furthermore, as knowledge is perceived as a source of power - setting those who hold it apart - it can be difficult to share. Nevertheless, individuals who believe that in sharing knowledge they lose power are wrong. Sharing knowledge is also a two way experience: by confronting other employees with new ideas, new skills can be acquired.

At the other extreme, the influx of data and information can overload the cognitive processing capacities of an individual. In this way, the acceleration of knowledge acquisition processes decreases his/her power of control.

Another barrier to the development of knowledge management is the lack of a knowledge-oriented, sharing culture. It is true to say that sharing knowledge does not naturally pair with labour: sharing the fruit of one's efforts can lead to loss of recognition for one's work. In the same way, the variety and dominance of 'subcultures' are harmful because the same knowledge can be expressed in different ways by various specialists (eg between marketing and computing staff).

In sum, technological barriers combine with the difficulties of learning new technologies and the general apprehension which accompanies change to inhibit the knowledge benefits which should arise.
Knowledge management contributes most when approached in a holistic manner that associates internal elements such as organisational culture, middle management leadership, organisational structure and business processes with customer-centric information systems. Collecting data and sharing information to improve the customer experience are two key factors of this process. This must be facilitated by strong management leadership, a customer-oriented organisational culture and technological amenities such as flexible and responsive information delivery channels and comprehensive customer knowledge available to front office employees. Knowledge management requires changes in employees' working practices. Leadership of proximity management is decisive in such an enterprise, using incentive, rewards and sanctions if necessary. ${ }^{29}$

\section{USING INFORMATION AND KNOWLEDGE TO DELIVER BETTER CUSTOMER EXPERIENCE}

Most CRM decisions are data driven and of course the famous 'garbage in, garbage out' (GIGO) rule applies: using spurious data leads at best to wasted money and at worst to wrong operational or strategic decisions. Creating models or scores on irrelevant data leads to incorrect information, to erroneous marketing decisions and to delivering poor customer experience.

The use of databases provides marketers with meaningful information on customer behaviour and enables management of the customer relationship - one of the main objectives being to sustain profitable and lasting transactional flows with each customer. CRM solutions provide a set of tools, enabling or facilitating comprehensive customer service organisation-wide. Unfortunately, 
despite the huge investments made in such programmes, many firms fail to integrate new business processes derived from database marketing knowledge within their information systems. The result is a somewhat frustrating customer experience due to lack of communication and coordination between the various departments he/she has to deal with, and an unsatisfactory employee experience, confronted with fragmented data systems and often inappropriate information. ${ }^{30}$ The system may appear innovative but, beneath the surface, it is still encumbered by poor communication and coordination between departments.

Ideally the outgoing data stream should distribute accurate, useful and relevant information to company staff who then can then aim to deliver excellent customer service or manufacture the appropriate products. The challenge is to understand and anticipate the needs of consumers to increase their satisfaction and loyalty. Once again, the availability of data is key to the ability to target customers and make relevant offers. Furthermore, in some industries, the call centre agent may be the only human that the customer has to deal with. He/she represents the entire image of the firm and must respond adequately to the customer's expectations. To this end, he/she must have all of the information that the firm has concerning this particular customer immediately to hand. In the authors' experience, the most successful implementations of marketing knowledge, such as segmentations, are those which are put into practice simultaneously by marketing and customer contact staff. This can mean duplicating the information in two separate campaign management and call centre systems and involves training sessions to interpret the segmentation from both the marketer and call centre agent's viewpoint.

Naturally, data, information and knowledge captured in a database cannot describe all of the knowledge that salespeople use to carry out their work. Their experience, their skills, their intuition, the relationships they build with the customers, their feelings and even their mood are of great importance in a service encounter. Data and information are guidelines for adjusting their behaviour in these moments of truth. On the other hand, when data or information about clients is too highly structured or aggregated, they may not provide the detail required for delivering customer excellence. One of the key operational problems to solve is to deliver, throughout all business systems, a common view of the customer and ensure that any updates to customer information are distributed in real time to every front office employee.

\section{CONCLUSION}

The data-led revolution is far from over. Not only will streams of real-time information accelerate and increase, but data analysis technologies will become widespread in all the sectors.

Organisations are currently aware of the importance of information at a micro level (customer behaviour and attitude) as well as at the macro level (market orientation, competition, expectations, innovation etc); however, they are experiencing difficulties in achieving a perfect information value chain due to technical and, above all, organisational and human reasons.

Important missing links in the data-customer value chain are data quality and marketing performance metrics. These should become an integral part of the database itself and contribute 
to optimising marketing and data quality investment. These decisions can in fact be grounded in common data.

Staff need to become increasingly skilled in transforming data to information and then using this information, combined with past experience, to accumulate knowledge. This knowledge structure will, in turn, help to identify the relevant data sources and perform targeted analysis to answer specific marketing questions. Sometimes it will be necessary for companies to seek outside help in bridging this gap between data and knowledge. If the data to knowledge loop is not closed, the continual improvement process cannot operate.

Knowledge management is a major strategic stake. Setting aside its technological aspects, it is a complex compound of organisational, cultural and human factors with intrinsic barriers to its implementation. The organisation's inability to cope with accelerating information streams, changes in business practices, reticence in sharing power and the lack of knowledge-oriented culture are significant examples.

In an ideal world, data would be complete, accurate, reliable, 100 per cent error free and constantly updated. All of the data necessary to perfectly understand the needs, desires and attitudes of the customer would available. A knowledge machine would transform data into information and then into knowledge. Computer hardware and software would deliver the right information, to the right people, at the right time, and everyone would be able to operate the system without effort. People within the organisation would work together with one goal: delivering a superior customer experience. Staff would be empowered and able to respond immediately to all types of customer complaints with the sole objective of enchanting the customer. Metrics would finally prove that the whole process is worthwhile for the company stakeholders.

\section{References}

1 Courtheoux, R. (2003) 'Marketing data analysis and data quality management', Journal of Targeting, Measurement and Analysis for Marketing, Vol. 11, No. 4, pp. 299-313.

2 Laurent, G. (2000) 'Improving the external validity of marketing models: A plea for more qualitative input', International Journal of Research in Marketing, Vol. 17, pp. 177-182.

3 Peppers D. and Rogers, M. (1999) One to One Fieldbook (One to One), Currency, New York, NY.

4 Fournier, S. (1998) 'Consumers and their brands: Developing relationship theory in consumer research', Journal of Consumer Research, Vol. 24, pp. 343-373.

5 Micheaux, A. and Gayet, A. (2001) 'Turning a marketing database into a relationship marketing database', Interactive Marketing Journal, Vol. 2, No. 4, pp. 327-346.

6 Peltier, J. W., Schibrowsky, J. A., Schultz, D. E. and Davis, J. (2002) 'Interactive psychographics: Cross-selling in the banking industry', Journal of Advertising Research, Vol. 42, No. 2, pp. 7-22.

7 Leeflang, P. S. and Wittink, D. R. (2000) 'Building for marketing decisions: Past, present and future', International Journal for Research in Marketing, Vol. 17, No. 1, pp. 105-126.

8 Wedel, M., Kamakura, W. and Böckenholt, U. (2000) 'Marketing data, models and decisions', International Journal of Research in Marketing, Vol. 17, No. 4, pp. 203-208.

9 Parasuraman, A. (1997) 'Reflections on gaining competitive advantage through customer value', Journal of the Academy of Marketing Science, Vol. 25, No. 2, pp. 154-61.

10 Bitran, G. R. and Mondschein, S. V. (1996) 'Mailing decisions in the catalog industry', Management Science, Vol. 42, No. 9, pp. 1364-1381.

11 Morrison, D. G. (1981) 'Modeling consumer purchase events: a reply to Lawrence' Journal of Marketing Research, Vol. XVIII, pp. 465-69.

12 Crié, D. (2002) 'When should a customer be considered as lapsed ?' Journal of Interactive Marketing, Vol. 3, No. 4, pp. 324-336.

13 Godin, S. (1999) Permission Marketing: Turning Strangers into Friends and Friends into Customers, Simon \& Schuster, New York, N.Y.

14 Stone, E. F., Gardner, D. G., Geugal, H. G. and McClure, S. (1983) 'A field experiment domparing information-privacy values, beliefs and attitudes across several types of organizations', Journal of Applied Psychology, Vol. 68, No. 3, pp. $459-468$.

15 Stone, M., Foss, B., Irwin D. et al. (2003) 'The 
quality of customer information management in customer life cycle management', Journal of Database Marketing \& Customer Strategy Management, Vol. 10, No. 3, pp. 240-254.

16 Clément, D. and Laboisse, B. (2006) 'Audit des données du 'référentiel client'de Hewlett Packard', presented at the second Data and Knowledge Quality Workshop, ECG, held at Villeneuve d'Ascq, France, on 17th January 2006.

17 Solomon, M. D. (2005) 'It's all about the data', Information Systems Management, Summer, 75-80.

18 Olson, J. E. (2002) Data Quality: The Accuracy Dimension, Morgan Kaufmann, San Francisco, CA.

19 Clément and Laboisse (2006) op cit.

20 Worthington, J. C. and Brilis, G. (2000) 'How good are my data? Information quality assessment methodology', Quality Assurance, Vol. 8, pp. 245-260.

21 Berti-Equille, L. (2006) 'A framework for profiling data pollution through composite services', presented at the IQIS 2006 Workshop, held in Chicago, IL on 30th June, 2006 (co-located with third International ACM SIGMOD Workshop on Information Quality in Information Systems, ACM SIGMOD/PODS 2006).

22 Courtheoux, R. J. (2003) 'Marketing data analysis and data quality management', Journal of Targeting, Measurement and Analysis for Marketing, Vol. 11, No. 4, pp. 299-313.

23 Clément and Laboisse (2006) op cit.

24 Boisot, M. and Canals, A. (2004) 'Data, information and knowledge: Have we got it right?', Journal of Evolutionary Economics, Vol. 14, pp. 43-67.

25 Michaels, S., Goucher, N.P. and McCarthy, D. (2006) 'Considering knowledge uptake within a cycle of transforming data, information, and knowledge', Review of Policy Research, Vol. 23, No. 1, pp. 267-279.

26 Hackathorn, R. (2004) 'The BI watch: Real-time to real value', DM Review, Vol. 114, No. 1, pp. 11-12.

27 Watson, H. J., Wixom, B. H., Hoffer, J. A. et al. (2006) 'Real-time business intelligence: Best practices at Continental Airlines', Information Systems Management, Winter, pp. 7-18.

28 Hackathorn (2004) op cit.

29 Stone et al. (2003) op cit.

30 Eichorn, F. L. (2004) 'Internal customer relationship management. A framework for achieving customer relationship management from the inside out, Problems and Perspectives in Management, Vol. 2004, No. 1, pp. 154-177. 